\title{
Tissue Culture Clonal Propagation of Hybrid White Oaks for the Urban Environment
}

\author{
Miles Schwartz Sax \\ 135 Plant Science Building, School of Integrative Plant Sciences, Section of \\ Horticulture, Cornell University, Ithaca, NY 14853
}

Nina Bassuk

33 Plant Science Building, School of Integrative Plant Sciences, Section of Horticulture, Cornell University, Ithaca, NY 14853

Mark Bridgen

3059 Sound Avenue, School of Integrative Plant Sciences, Section of Horticulture, Cornell University, Riverhead, NY 11901

Additional index words. environmental stress, plant selection, plant preservative mixture (PPM), Quercus, woody plant medium, Urban Horticulture Institute (UHI), urban trees

\begin{abstract}
A tissue culture system was developed to clonally propagate a series of hybrid white oaks (Quercus L.) at the plant breeding program of the Urban Horticulture Institute (UHI), Cornell University. From 2014 through 2018, 34 genotypes and 1966 individual explants of UHI hybrid white oaks were trialed to determine their capacity to establish, multiply, and root in a tissue culture environment. UHI hybrid oak genotypes were selected based on their known tolerance to stresses common in the urban environment (drought, alkaline soils, pests, and diseases) and their ornamental qualities. Individual genotype was the single largest factor affecting successful establishment, multiplication, stabilization, and rooting of hybrid oaks in vitro. Thirteen clones of hybrid oaks were identified as having the capacity to stabilize and grow continuously in the multiplication phase. Multiplication efficiency rates were dependent on individual genotype. Stabilized genotypes showed the capacity to be re-established during successive years. The tissue culture process was simplified and refined to make the protocols less labor intensive for laboratory technicians using these methods. This study presents a preliminary and promising method for the clonal propagation of oak species and provides a path for cultivar development for plants belonging to the genus Quercus.
\end{abstract}

Clonal propagation of oaks has long been recognized as a major challenge to selection, breeding, and improvement of the genus Quercus L. for horticultural and forestry applications. Growing Quercus from seed has been the traditional means of oak propagation (Dirr, 1987). Because of the hybridization among Quercus species and a high degree of intraspecific variation within species, oaks can express high variability in their phenotypes (Nixon, 1997). As a result, oak nursery stock tends to be variable in its tolerance to abiotic and biotic stressors, making selection and evaluation difficult. The grafting of oaks is reported as a viable method to produce asexual clones for a limited number of species (Dirr, 1987). For example, the English Oak (Quercus robur L.)

Received for publication 27 June 2019. Accepted for publication 22 Sept. 2019.

Current address for M.S.S.: Arboretum Director, Adjunct Associate Professor of Botany, Connecticut College, 103 Olin Science Center, New London, CT 06320.

M.S.S. is the corresponding author. E-mail: msax@ conncoll.edu. has at least 262 named cultivars, many of which have been propagated by grafting and have the capacity to grow into the mature life phase (International Oak Society, 2018). Propagation using grafting methods has had limited success with a wider variety of species primarily because of the occurrence of delayed graft incompatibility (Coggeshall, 1996; Dirr, 1987; Santamour and Coggeshall, 1996). Cornell's UHI has successfully developed a rooting protocol that uses a modified stool-bed method offering an alternative means of clonal oak propagation (Amissah and Bassuk, 2009; Griffin and Bassuk, 1996).

The breeding and development of oak cultivars has been a long-term goal for the UHI. The genus Quercus is a species-rich clade of long-lived trees that inhabit a wide variety of ecological conditions across their natural range and provide a rich genetic source for plant breeding material (Cavender-Bares, 2019). Oaks are generally known to be drought tolerant, making them ideal candidates for planting in typically low soil moisture conditions found in the urban environment (Abrams, 1990; Osuna et al., 2015; Sjöman et al., 2018). Oaks are commonly a major component of urban forests across eastern North American cities and are frequently requested by residents as a desirable street tree (Raupp et al., 2006). Despite the popularity of oaks as street trees, their tolerance to urban site conditions is often mixed due to the genetic variability of seed sources from which the trees are grown. Development of oak cultivars would allow for assessing specific genotypes for their tolerance to urban stressors and lead to increased health and performance of oaks in the urban forest.

The development of a modified stool-bed method of clonal oak propagation has removed a key technical barrier to initiating an oak breeding program (Amissah and Bassuk, 2009; Griffin and Bassuk, 1996). With the propagation constraint overcome, a white oak breeding program was undertaken by the UHI from 2004 to 2006 and resulted in the development of 345 unique interspecific genotypes. Crosses were made with seven maternal parent taxa and 36 paternal parent taxa from species native to North America, Europe, and Asia (Denig et al., 2013). Paternal germplasm selection focused on species that grow under natural conditions that were analogous to stressors found in the urban environment such as regions with high soil $\mathrm{pH}$ or frequent droughts. Hybrid oak seedlings from the breeding program were grown continuously at Cornell's Bluegrass Lane Turf and Landscape Research Center [USDA plant hardiness zone $5 b\left(-15\right.$ to $\left.\left.-10^{\circ} \mathrm{F}\right)\right]$ in Ithaca, NY. In 2013, a variation of the stoolbed method was successfully applied to UHI hybrid white oaks resulting in a series of rooted trees that were then evaluated (Denig et al., 2013). Evaluation of UHI hybrid oaks for tolerance to the urban environment has included screening hybrid oaks for alkaline tolerance in high $\mathrm{pH}$ soils (Denig et al., 2014); a study of UHI hybrid oaks capacity to use the osmotic adjustment drought tolerance mechanism for trees growing under field conditions (Schwartz Sax, 2019); pest (Cynipid wasp gal, Japanese beetles); and disease (powdery mildew, anthracnose) tolerance (Schwartz Sax, 2019). Additionally, evaluation of UHI hybrid oaks was undertaken to assess tree form, leaf morphology, fall color, ornamental quality, and general performance growing under nursery and field conditions.

While the modified stool-bed method proved successful for the clonal propagation of a series of hybrid white oaks, the number of individual trees produced in an annual cycle was low for most genotypes (Denig et al., 2013). For example, UHI hybrid oak genotypes annually produced an average four to eight shoots per individual stock plant. For each of these shoots, the probability of producing roots ranged from $19.4 \%$ to $60.0 \%$, depending on genotype and maternal parentage (Denig et al., 2013). This limitation reduced the commercial viability of the stool-bed rooting method. To overcome this limitation, tissue culture protocols were trialed to determine if in vitro methods could successfully be used to clonally propagate UHI hybrid oaks.

The use of oak tissue culture methods used to grow plants beyond an organoid phase 
was first reported 1985, and the methods have continued to be refined and improved (Vieitez et al., 1985, 2012). Contemporary oak tissue culture methods primarily include shoot cultures and somatic embryogenesis (Vieitez et al., 2012). Shoot culture methods have been used to successfully grow taxa of conservation concern (Brennan et al., 2017; Kramer and Pence, 2012) and economically important North American species in the white oak sections (sect. Quercus) and red oak sections (sect. Lobatae) (Vieitez et al., 2009). Although shoot culture methods have successfully been applied to a series of oak species, specific challenges exist in the tissue culture process. These challenges have included relatively few genotypes within a given species being responsive to the tissue culture environment (genotype specificity) (Herrmann and Buscot, 2008; San-José et al., 1988; Vengadesan and Pijut, 2009; Vieitez et al., 1993, 1994, 2009); terminal shoot tips dying after prolonged periods of growing in tissue culture medium (shoot tip necrosis) (Schwarz and Schlarbaum, 1993; Vieitez et al., 1994, 2009); and episodic growth patterns of oaks in tissue culture (Herrmann and Buscot, 2008; Vieitez et al., 2009). While these challenges have limited the widespread adoption of using tissue culture protocols for oak propagation, these methods continue to be researched and improved (Vieitez et al., 2012).

The primary objective of this study was to determine the suitability of using tissue culture methods to clonally propagate UHI hybrid oaks. To overcome specific challenges in oak tissue culture, a series of experiments were designed to improve the process. Specific objectives of this study included trialing a variety of hybrid oak germplasm for their capacity to successfully grow in the tissue culture environment and streamlining the tissue culture protocols for technicians and practitioners. The long-term goal of the UHI breeding program is to release tissue-culture propagated, stress tolerant UHI hybrid oak cultivars to the nursery and arboriculture industries.

\section{Materials and Methods}

\section{Hybrid oak selection}

Hybrid white oak genotypes chosen for trialing in the tissue culture system were from the UHI breeding program and were selected based on their performance growing under field conditions and in stress evaluation studies (Schwartz Sax, 2019) (Table 1).

\section{Stock plant management and shoot harvesting}

Select UHI hybrid oak genotypes were harvested from stool-bed grown stock plants for establishment in tissue culture. Stool-bed stock plants were coppiced annually in Apr., removing the growth of the previous year. One-year-old stems were retained and placed in a flower vase (16 in high) with $2 \mathrm{~L}$ of water in a growth chamber. The growth chamber was maintained with a $12-\mathrm{h}$ photoperiod starting at 10:00 $\mathrm{AM}$, with an average temperature of $70^{\circ} \mathrm{F}$, ambient $\mathrm{CO}_{2}$, and 200 to 500 $\mu \mathrm{mol} / \mathrm{m}^{2} / \mathrm{s}$ light from T5 cool white fluores- cent bulbs. The stems were maintained in this condition until buds broke dormancy. The flush of new shoots from these buds were harvested after 4 to 6 weeks and upon reaching a length of $5 \mathrm{~mm}$ or more.

A second source of shoots used for establishment were collected between mid-May and early June when new shoots emerged from the coppiced field-grown stock plants. The coppicing technique forced juvenile epicormic shoots to emerge from a position close to the root shoot interface (Denig et al., 2013). Shoots were harvested directly from the field once they were $10 \mathrm{~cm}$ or more in height. Field-harvested shoots were stored in $50-\mathrm{mL}$ Falcon tubes in a cooler with crushed ice while being transferred to the laboratory for decontamination. Shoots that were taller than the Falcon tube were cut into sections and placed in the same tube.

\section{Disinfestation}

In the laboratory, $50 \mathrm{~mL} 70 \%$ ethanol $(\mathrm{EtOH})$ was poured into each Falcon tube, and all the tubes were placed on an orbital shaker set to $200 \mathrm{rpm}$ for $1 \mathrm{~min}$. After shaking, all tubes were moved into a laminar flower hood and the EtOH was discarded. In the flow hood, $50 \mathrm{~mL}$ of a bleach (7.4\% sodium hypochlorite) and Tween 80 solution $\left(20 \%\right.$ bleach, $80 \%$ DI $\mathrm{H}_{2} \mathrm{O}$ with two to three drops of Tween 80 per 100 $\mathrm{mL}$ ) were added to each Falcon tube and capped. Falcon tubes were placed on an orbital shaker at $200 \mathrm{rpm}$ for a period of $15 \mathrm{~min}$ before returning to the flow hood, where the bleach/ Tween solution was discarded. The shoots and tubes were rinsed three times with autoclaved sterile deionized water.

\section{Establishment}

Disinfected shoots were cut into one-bud segments that were 50 to $100 \mathrm{~mm}$ long. Buds were harvested sequentially, starting at the proximal end of the shoot to the cut surface and proceeding toward the terminal bud. Individual buds were placed upright into $25-\times 150-\mathrm{mm}$ culture tubes filled with 15 $\mathrm{mL}$ establishment medium. The oak establishment medium consisted of Lloyd and McCown Woody Plant Medium $2.41 \mathrm{~g} / \mathrm{L}$, 6-benzylaminopurine (BAP) $0.5 \mathrm{mg} / \mathrm{L}$ $(2.22 \mu \mathrm{M})$, sucrose $30 \mathrm{~g} / \mathrm{L}$, and agar $5.5 \mathrm{~g} /$ $\mathrm{L}$; $\mathrm{pH}$ was adjusted to $5.6 \pm 0.1$. All tissue culture medium hormones, sucrose, agar, and other additives for experiments were sourced from Phytotechnology Laboratories, Lenexa, KS. After 1 to $3 \mathrm{~d}$, individual buds were moved from one side of the culture tube to the opposite side when necessary to avoid oxidized phenolics that had exuded from cut surfaces. If phenolic secretion and oxidation continued after initial movement, buds were then moved to a new test tube with establishment medium. Explants were transferred to fresh medium every 2 weeks. After 6 weeks, individual buds that elongated to a length equal to or more than $5 \mathrm{~mm}$ were moved to the multiplication phase.

In 2018, an establishment experiment was conducted to determine the efficacy of Plant Preservative Mixture (PPM) on reducing con- tamination rates during establishment. PPM is a broad spectrum, nonselective, fungicidal, and biocidal compound, and it was added when mixing medium at a rate of $0.1 \%$ (Niedz, 1998). All shoots used for the PPM experiment were harvested from the stock block at Bluegrass Lane Turf and Landscape Research Center under field conditions.

\section{Multiplication}

Standard multiplication medium. Oak tissue culture multiplication methods and medium were based on research presented by Vieitez et al. (2009). The apical dome, including $2 \mathrm{~mm}$ of the terminal bud, and all leaves were removed from the shoot when transferring it from establishment to multiplication phase. Trimmed shoots were placed horizontally in a 111-mL baby food jar with $25 \mathrm{~mL}$ of multiplication medium. Horizontal shoot placement allows for lateral buds to elongate into new shoots (Vieitez et al., 2009). The oak multiplication medium was composed of Woody Plant Medium $2.41 \mathrm{~g} / \mathrm{L}$, BAP $0.5 \mathrm{mg} / \mathrm{L}$, sucrose $30 \mathrm{~g} / \mathrm{L}$, and agar 5.5 $\mathrm{g} / \mathrm{L} ; \mathrm{pH}$ was adjusted to $5.6 \pm 0.1$. Shoots were subcultured and transferred to a fresh medium at 2-week intervals. After a period of 6 weeks, new shoots that had emerged from lateral buds were harvested, and the multiplication cycle was repeated. Over successive multiplication cycles, individual genotype lines either increased and stabilized, or decreased and died out. Stabilized lines had the capacity to generate enough new shoots at the end of a multiplication cycle to be able to grow continuously (Table 2). Stabilized lines were used to conduct multiplication, rooting, and acclimatization experiments

Zeatin PVP medium. Experimentation in the multiplication phased included modifications to the standard medium. The cytokinin zeatin and the phenolic binding compound polyvinylpyrrolidone (PVP) (mol. weight 40,000) were trialed as a replacement for BAP. PVP was assessed in a multiplication medium to determine its capacity to prevent oxidation of phenolic compounds released into the medium when shoots were damaged by cutting at the start of the multiplication phase. Stabilized hybrid oak genotypes (05830-50, 06-1500-1, 06-1500-6, 06-1819-1, and $06-1821-3$ ) that had previously been grown continuously in the standard multiplication medium were used for this experiment. The zeatin PVP medium treatment was composed of Woody Plant Medium $2.41 \mathrm{~g} / \mathrm{l}$, zeatin $0.5 \mathrm{mg} / \mathrm{L}(2.28 \mu \mathrm{M})$, sucrose $30 \mathrm{~g} / \mathrm{L}$, MES (2-(N-morpholino) ethanesulfonic acid) $0.5 \mathrm{~g} / \mathrm{L}$, PVP40 $0.5 \mathrm{~g} / \mathrm{L}$, and Phytoblend $5.5 \mathrm{~g} / \mathrm{L} ; \mathrm{pH}$ was adjusted to $5.6 \pm 0.1$. For the first 2 weeks of the multiplication phase, shoots were placed in $25 \mathrm{~mL}$ zeatin PVP medium in 111-mL baby food jars. For the control treatment, $25 \mathrm{~mL}$ standard BAP medium was used. After 2 weeks in culture and before the first subculturing transfer, the medium was visually assessed to determine if phenolic oxidation occurred. Phenolic exudation was characterized by an absence or presence of oxidized phenolic compounds, 
Table 1. Hybrid oak genotypes trialed in tissue culture with identification numbers corresponding maternal and paternal parentages.

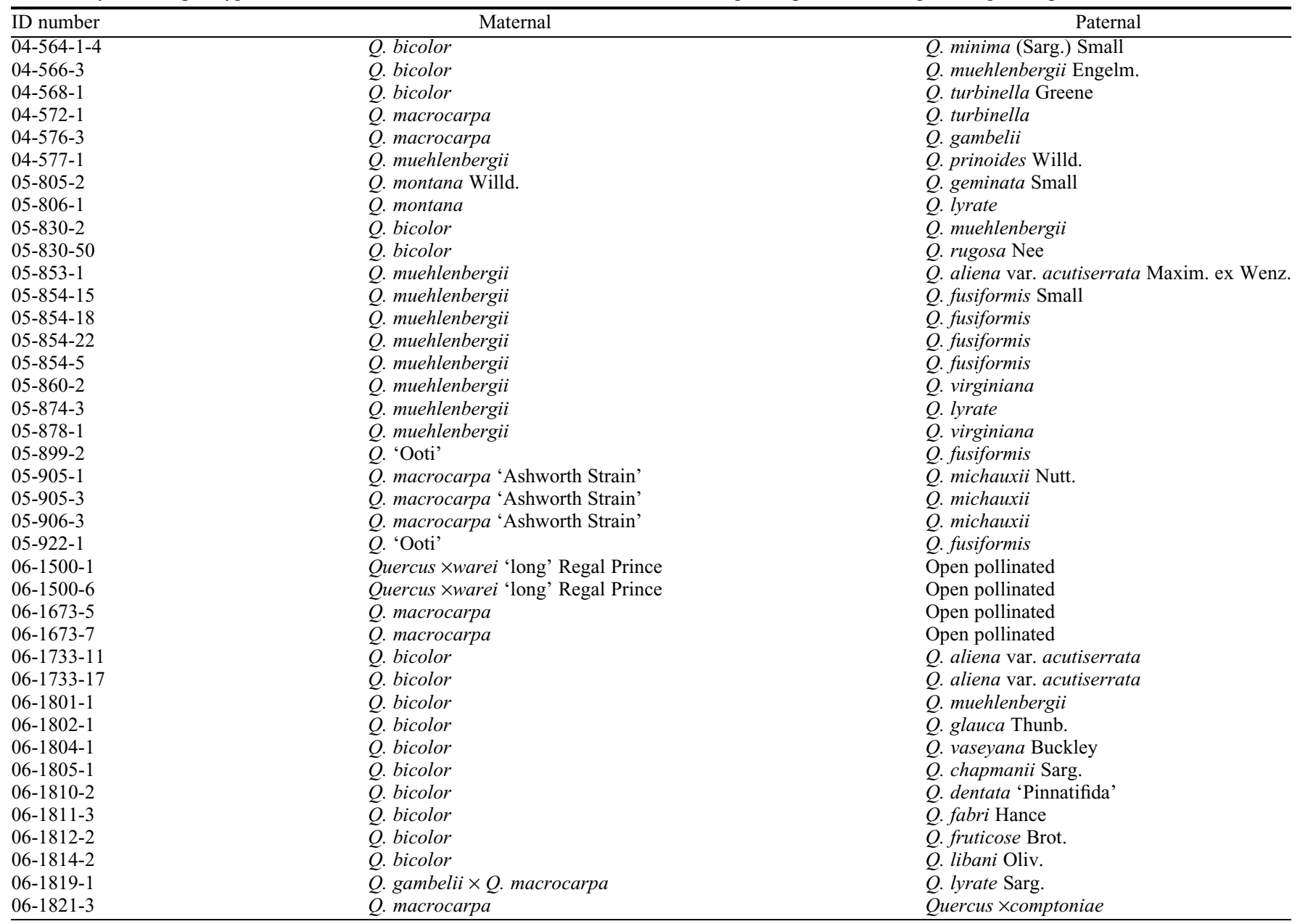

Table 2. Stabilized UHI hybrid oak lines growing continuously in multiplication phase.

\begin{tabular}{lllr}
\hline Genotype & \multicolumn{1}{c}{ Maternal } & \multicolumn{1}{c}{ Paternal } \\
\hline $06-1819-1^{z}$ & Quercus gambelii $\times$ macrocarpa & Yr established \\
$06-1500-1^{z}$ & Quercus $\times$ warei 'long' Regal Prince & Q. lyrate & 2014 and 2017 \\
$06-1500-6^{z}$ & Quercus $\times$ warei 'long' Regal Prince & Open pollinated & 2014 and 2017 \\
$04-564-1-4$ & Q. bicolor & Open pollinated & 2014 and 2017 \\
$05-805-2$ & Q. montana & Q. minima & 2015 \\
$05-806-1$ & Q. montana & Q. geminata & 2015 \\
$05-860-2$ & Q. muehlenbergii & Q. lyrate & 2015 \\
$05-878-1$ & Q. muehlenbergii & Q. virginiana & 2015 \\
$04-568-1$ & Q. bicolor & Q. turbinella & 2015 \\
$05-830-50$ & Q. bicolor & Q. rugosa & 2016 \\
$06-1673-7$ & Q. macrocarpa & Open pollinated & 2016 \\
$06-1802-1$ & Q. bicolor & Q. glauca & 2016 \\
$06-1804-1$ & Q. bicolor & Q. vaseyana & 2016 \\
$06-1811-3$ & Q. bicolor & Q. fabri & 2016 \\
$06-1812-2$ & Q. bicolor & Q. fruticosa & 2016 \\
$06-1821-3$ & Q. macrocarpa & Quercus $\times$ comptoniae \\
$04-566-3$ & Q. bicolor & Q. muehlenbergii & \\
$06-1810-2$ & Q. bicolor & Q. dentata 'Pinnatifida' \\
$05-854-15$ & Q. muehlenbergii & Q. fusiformis & 2016 \\
\hline
\end{tabular}

${ }^{\mathrm{z}}$ Genotype lines that were re-established into a continuous multiplication cycle during in different years.

which appeared as a darkening and browning of the medium. After the phenolic oxidation assessment was complete, shoots in the zeatin PVP treatment were transferred to a new baby food jar with $50 \mathrm{~mL}$ standard BAP multiplication medium and allowed to develop for a period of 4 weeks with no further subculturing. Control treatments were subcultured at the standard 2-week interval with
$25 \mathrm{~mL}$ BAP multiplication medium. At the end of the 6-week multiplication period, both treatments were assessed for contamination, number of shoots produced, and shoot length.

Subculture transfer time (1-5 vs. 2-2-2). An experiment was designed to determine if the number of times a shoot was subcultured during the 6-week multiplication phase affected the number of shoots produced and shoot length. Stabilized hybrid oak genotypes (05-830-50, 06-1500-1, 06-1819-1, and 061821-2) that had previously been grown in standard multiplication medium were used for this experiment. The control treatment for the study was the standard subculturing at 2week intervals for a total of 6 weeks and was denoted as $2-2-2$. The alternative treatment was subculturing shoots after 1 week and 


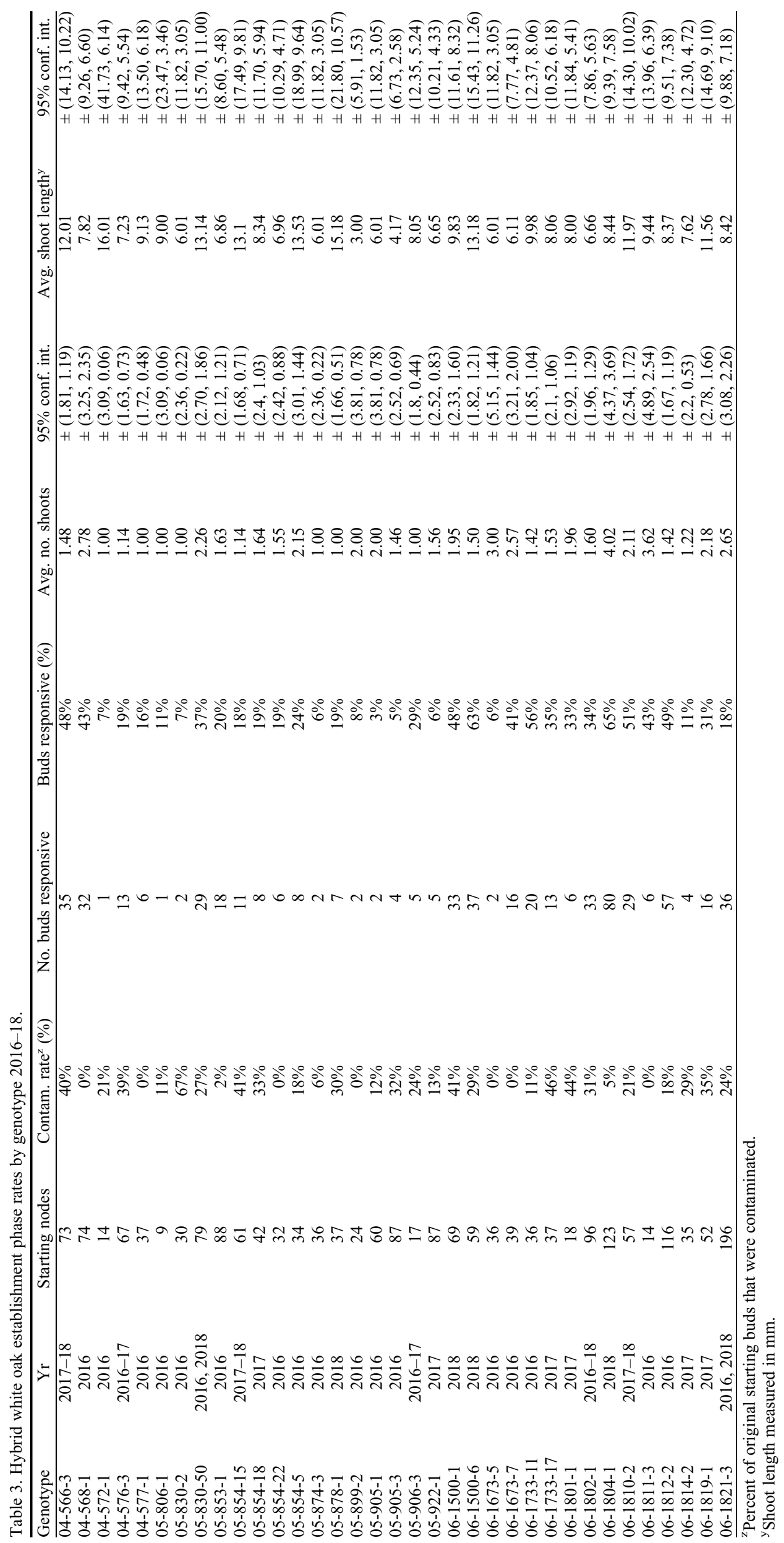


Table 4. Effect of using whole shoots vs. shoot tips on multiplication rates of hybrid oaks.

\begin{tabular}{|c|c|c|c|c|c|c|}
\hline Genotype & Shoot vs. tip & $\mathrm{n}$ & Contam. rate ${ }^{\mathrm{z}}$ & Avg. no. shoots & Avg. shoot length ${ }^{y}$ & $95 \%$ conf. int. \\
\hline $05-830-50$ & Shoot & 20 & $0 \%$ & $1.23 \pm 0.23 \mathrm{a}$ & $10.11 \mathrm{a}$ & $\pm(12.96,7.88)$ \\
\hline $05-830-50$ & Tip & 19 & $0 \%$ & $2.31 \pm 0.41 \mathrm{a}$ & $14.76 \mathrm{a}$ & $\pm(17.96,12.13$ \\
\hline $06-1500-1$ & Shoot & 40 & $0 \%$ & $5.21 \pm 0.41 \mathrm{a}$ & $14.05 \mathrm{a}$ & $\pm(15.96,12.37$ \\
\hline 06-1500-1 & Tip & 40 & $0 \%$ & $2.99 \pm 0.31 \mathrm{~b}$ & $13.56 \mathrm{a}$ & $\pm(15.37,11.96$ \\
\hline $06-1500-6$ & Shoot & 37 & $3 \%$ & $0.85 \pm 0.18 \mathrm{a}$ & $7.56 \mathrm{a}$ & $\pm(8.90,6.42)$ \\
\hline $06-1500-6$ & Tip & 37 & $5 \%$ & $1.09 \pm 0.23 \mathrm{a}$ & $7.67 \mathrm{a}$ & $\pm(8.76,6.71)$ \\
\hline $06-1819-1$ & Shoot & 30 & $3 \%$ & $3.98 \pm 0.41 \mathrm{a}$ & $13.66 \mathrm{a}$ & $\pm(15.80,11.81)$ \\
\hline 06-1819-1 & Tip & 30 & $0 \%$ & $2.71 \pm 0.37 \mathrm{a}$ & $13.61 \mathrm{a}$ & $\pm(15.87,11.66)$ \\
\hline $06-1821-3$ & Shoot & 37 & $0 \%$ & $0.84 \pm 0.18 \mathrm{a}$ & $9.72 \mathrm{a}$ & $\pm(11.58,8.15)$ \\
\hline $06-1821-3$ & Tip & 37 & $0 \%$ & $\begin{array}{c}1.57 \pm 0.27 \mathrm{a} \\
\text { Prob }>F\end{array}$ & $\begin{array}{c}8.09 \mathrm{a} \\
\text { Prob }>F\end{array}$ & $\pm(9.27,7.05)$ \\
\hline Genotype (A) & & & & $<0.0001$ & $<0.0001$ & \\
\hline Treatment (B) & & & & 0.3499 & 0.5217 & \\
\hline$A \times B$ & & & & $<0.0001$ & 0.0837 & \\
\hline
\end{tabular}

${ }^{\mathrm{z}}$ Percent of original starting buds that were contaminated.

${ }^{\mathrm{y}}$ Shoot length measured in $\mathrm{mm}$.

Table 5. Rooting capacity of hybrid white oaks treated with IBA.

\begin{tabular}{|c|c|c|c|c|c|c|}
\hline Genotype & $\mathrm{n}$ & Rooting & Avg. no. roots & SD error & Avg. root length ${ }^{z}$ & $95 \%$ conf. int. \\
\hline $05-830-50$ & 15 & $67 \%$ & $1.67 \mathrm{~b}$ & 0.77 & $10.50 \mathrm{~b}$ & $\pm(17.94,6.15)$ \\
\hline $06-1500-1$ & 15 & $87 \%$ & $3.73 \mathrm{~b}$ & 0.77 & $11.67 \mathrm{~b}$ & $\pm(18.67,7.30)$ \\
\hline $06-1500-6$ & 12 & $100 \%$ & $10.00 \mathrm{a}$ & 0.86 & $31.06 \mathrm{a}$ & $\pm(50.65,19.05)$ \\
\hline $06-1819-1$ & 15 & $60 \%$ & $1.87 \mathrm{~b}$ & 0.77 & $8.92 \mathrm{~b}$ & $\pm(15.69,5.07)$ \\
\hline \multirow[t]{2}{*}{$06-1821-3$} & 12 & $67 \%$ & $3.17 \mathrm{~b}$ & 0.86 & $26.02 \mathrm{a}$ & $\pm(47.35,14.29)$ \\
\hline & & & Prob $>F$ & & Prob $>F$ & \\
\hline Genotype & & & $<0.0001$ & & 0.0029 & \\
\hline
\end{tabular}

${ }^{\mathrm{z}}$ Root length measured in $\mathrm{mm}$.

maintaining them for 5 additional weeks, and this method was denoted as $1-5$. For each genotype, the experiment was replicated with 40 individual shoots, and data were collected at the end of the 6-week multiplication cycle. Data collected included percent of cultures contaminated, number of shoots produced, and shoot length.

Shoot vs. tip. Methods used in previous oak tissue culture studies (Vieitez et al., 2009) recommended using shoots with terminal buds removed in the multiplication phase. An experiment was designed to determine if the removed terminal buds could be retained and develop new shoots in the multiplication phase. Five genotypes (05-830-50, 06-15001,06-1500-6, 06-1819-1, and 06-1821-3) were used for the experiment. Shoots tips were about $3 \mathrm{~mm}$ long and contained the terminal bud and a varying number of lateral buds. Two shoots and their accompanying tips were placed in a single $111-\mathrm{mL}$ baby food jar with $25 \mathrm{~mL}$ standard multiplication medium. Shoots and tips were subcultured at 2-week intervals and assessed after 6 weeks. At the end of each multiplication cycle, the number of shoots and shoot length were assessed and averaged by genotype.

\section{Rooting}

Standard rooting method. Shoots more than $5 \mathrm{~mm}$ in height with living terminal buds were selected at the end of multiplication cycles and moved to rooting. Shoot length and number of leaves were recorded. An idole-3-butyric acid (IBA) rooting medium was used for the rooting induction phase. An IBA root induction medium was composed of Woody Plant Medium $2.41 \mathrm{~g} / \mathrm{L}$, IBA $25 \mathrm{mg} / \mathrm{L}$ (122.5 $\mu \mathrm{M})$, sucrose $30 \mathrm{~g} / \mathrm{L}$, and Phytoblend
$5.5 \mathrm{~g} / \mathrm{L} ; \mathrm{pH}$ was adjusted to $5.6 \pm 0.1$. Explants were maintained for a period of $7 \mathrm{~d}$ in the IBA induction medium before being transferred to a medium without plant growth regulators (PGR) for 2 weeks. This PGR-free medium consisted of Woody Plant Medium $2.41 \mathrm{~g} / \mathrm{L}$, active charcoal $4 \mathrm{~g} / \mathrm{L}$ at $\mathrm{pH}$ 5.7, sucrose $30 \mathrm{~g} / \mathrm{L}$, and Phytoblend $5.5 \mathrm{~g} / \mathrm{L}$; $\mathrm{pH}$ was adjusted to $5.6 \pm 0.1$ For both induction and PGR-free phases, $15 \mathrm{~mL}$ medium was used per culture tube $(25 \times 150 \mathrm{~mm})$. Each shoot was placed in a single tube during the rooting phase. After the 2 weeks in the PGR-free medium, root development was assessed. Measurements included occurrence of shoot tip necrosis, total number of roots produced, and root length.

$K-I B A$ vs. IBA. For two genotypes (061500-6 and 06-1821-3), an experiment was conducted to determine the effectiveness of KIBA compared with IBA for the root induction. The K-IBA rooting medium was the same as a standard rooting medium except for the substitution of K-IBA for IBA at a rate of $25 \mathrm{mg} / \mathrm{L}$ $(103.5 \mu \mathrm{M})$. Explants were kept in IBA or KIBA medium for $2 \mathrm{~d}$ before the transfer to a PGR-free medium for $30 \mathrm{~d}$. The number of roots and root length were assessed at the end of the period.

Statistics. Statistical analysis was conducted using JMP Pro v14.0. Primary statistics used for data analysis included chi-square, Fisher's exact two-tailed test, analysis of variance, mixed effect models, and Tukey's honestly significant difference matching letter analysis. An alpha level of 0.05 was used for hypothesis testing to determine statistical significance. For Tukey's honestly significant difference tests, matching letters indicate similar mean values. Data transformations were used for data that did not have normal distributions. Negative binomial statistics were used for data exhibiting negative binomial distribution. For mixed effect models with multiple comparisons, a Bonferroni correction was used to normalize $P$ values. Specific transformation cases are as follows: the average number of shoots in Table 3 were analyzed using a negative binomial model; mean root length (Tables 4 and 5) was normalized with a $\log$ transformation; a square root transformation was used for the number of shoots (Tables 6 and 7). Mean number of shoots produced during PPM establishment underwent square root transformation, and shoot length was log transformed (Table 8). Residuals of all other data were normally distributed and therefore were not transformed.

\section{Results}

\section{Establishment}

From 2016 to 2018, a total of 1966 buds were used for the establishment phase (Table 9). Successful establishment rates were not dependent on location of stock plants (field grown or growth chamber). Contamination rates were lower in shoots sourced from the growth chamber than from the field. Differences in contamination rates varied by year (Table 9). The number of buds started in tissue culture varied by genotype (Table 3). Of the 1966 buds attempted in culture, $585(30 \%)$ were responsive and grew in the establishment medium (Table 3). Individual bud responsiveness was variable depending on genotype and ranged from $0 \%$ to $100 \%$. The average number of shoots produced per individual starting bud and 
Table 6. Effect of medium type (BAP vs. zeatin PVP) on multiplication rates of hybrid oaks.

\begin{tabular}{|c|c|c|c|c|c|c|c|}
\hline Genotype & Medium & $\mathrm{n}$ & Contam. rate ${ }^{z}$ & Avg. no. shoots & $95 \%$ conf. int. & Avg. shoot length ${ }^{\mathrm{y}}$ & $95 \%$ conf. int. \\
\hline \multirow[t]{2}{*}{$05-830-50$} & BAP & 20 & $10 \%$ & $0.73 \mathrm{a}$ & $\pm(1.46,0.25)$ & $11.82 \mathrm{a}$ & $\pm(17.12,8.17)$ \\
\hline & ZeaPVP & 20 & $5 \%$ & $0.02 \mathrm{~b}$ & $\pm(0.24,0.04)$ & $6.82 \mathrm{a}$ & $\pm(14.3,3.25)$ \\
\hline \multirow[t]{2}{*}{ 06-1500-1 } & BAP & 61 & $8 \%$ & $3.55 \mathrm{a}$ & $\pm(4.34,2.84)$ & $12.06 \mathrm{a}$ & $\pm(14.01,10.49)$ \\
\hline & ZeaPVP & 60 & $13 \%$ & $2.78 \mathrm{a}$ & $\pm(3.48,2.16)$ & $12.94 \mathrm{a}$ & $\pm(15.03,11.25)$ \\
\hline \multirow[t]{2}{*}{$06-1500-6$} & BAP & 60 & $3 \%$ & $2.27 \mathrm{a}$ & $\pm(2.89,1.72)$ & $10.18 \mathrm{a}$ & $\pm(11.82,8.76)$ \\
\hline & ZeaPVP & 54 & $4 \%$ & $0.28 \mathrm{~b}$ & $\pm(0.55,0.10)$ & $7.46 \mathrm{a}$ & $\pm(9.39,5.93)$ \\
\hline \multirow[t]{2}{*}{ 06-1819-1 } & BAP & 50 & $16 \%$ & $1.85 \mathrm{a}$ & $\pm(2.44,1.34)$ & $9.78 \mathrm{a}$ & $\pm(11.36,8.41)$ \\
\hline & ZeaPVP & 46 & $6 \%$ & $0.72 \mathrm{~b}$ & $\pm(1.13,0.40)$ & $6.36 \mathrm{~b}$ & $\pm(7.69,5.21)$ \\
\hline \multirow[t]{3}{*}{$06-1821-3$} & BAP & 54 & $11 \%$ & $1.06 \mathrm{a}$ & $\pm(1.43,0.69)$ & $9.39 \mathrm{a}$ & $\pm(11.13,7.92)$ \\
\hline & ZeaPVP & 58 & $3 \%$ & $1.07 \mathrm{a}$ & $\pm(1.51,0.70)$ & $9.12 \mathrm{a}$ & $\pm(10.7,7.77)$ \\
\hline & & & & Prob $>F$ & & Prob $>F$ & \\
\hline Genotype (A) & & & & $<0.0001$ & & $<0.0001$ & \\
\hline Treatment (B) & & & & $<0.0001$ & & 0.0106 & \\
\hline$A \times B$ & & & & $<0.0001$ & & 0.0121 & \\
\hline
\end{tabular}

${ }^{\mathrm{z}}$ Percent of original starting buds that were contaminated.

${ }^{\mathrm{y}}$ Shoot length measured in millimeters.

Table 7. Effect of subculture transfer frequency on multiplication rates of hybrid oaks.

\begin{tabular}{|c|c|c|c|c|c|c|}
\hline Genotype & Transfer frequency (wks) & $\mathrm{n}$ & Contam. rate & Avg. no. shoots & Avg. shoot length ${ }^{\mathrm{y}}(\mathrm{mm})$ & $95 \%$ conf. int. \\
\hline $05-830-50$ & $1-5^{x}$ & 40 & $10 \%$ & $1.4 \pm 0.2 \mathrm{a}$ & $13.68 \mathrm{a}$ & $\pm(16.57,11.30)$ \\
\hline $05-830-50$ & $2-2-2^{x}$ & 40 & $0 \%$ & $1.0 \pm 0.2 \mathrm{a}$ & $13.28 \mathrm{a}$ & $\pm(16.15,10.92)$ \\
\hline $06-1500-1$ & $1-5$ & 40 & $30 \%$ & $2.3 \pm 0.3 \mathrm{a}$ & $11.10 \mathrm{a}$ & $\pm(13.01,9.47)$ \\
\hline $06-1500-1$ & $2-2-2$ & 40 & $10 \%$ & $3.4 \pm 0.4 \mathrm{a}$ & $12.07 \mathrm{a}$ & $\pm(14.11,10.32)$ \\
\hline $06-1819-1$ & $1-5$ & 40 & $20 \%$ & $2.3 \pm 0.3 \mathrm{a}$ & $10.08 \mathrm{a}$ & $\pm(11.76,8.64)$ \\
\hline $06-1819-1$ & $2-2-2$ & 40 & $10 \%$ & $3.2 \pm 0.4 \mathrm{a}$ & $12.81 \mathrm{a}$ & $\pm(14.87,11.03)$ \\
\hline $06-1821-3$ & $1-5$ & 40 & $0 \%$ & $1.2 \pm 0.2 \mathrm{a}$ & $5.42 \mathrm{a}$ & $\pm(6.41,4.59)$ \\
\hline $06-1821-3$ & $2-2-2$ & 40 & $0 \%$ & $1.6 \pm 0.2 \mathrm{a}$ & $7.27 \mathrm{a}$ & $\pm(8.62,6.14)$ \\
\hline & & & & Prob $>$ ChiSq & Prob $>F$ & \\
\hline Genotype (A) (B) & & & & $<0.0001$ & $<0.0001$ & \\
\hline Treatment (B) & & & & 0.1366 & 0.016 & \\
\hline$A \times B$ & & & & 0.0537 & 0.2555 & \\
\hline
\end{tabular}

${ }^{\mathrm{z}}$ Percent of original starting buds that were contaminated.

${ }^{\mathrm{y}}$ Shoot length measured in millimeters.

${ }^{\mathrm{x}} 1-5$ and $2-2-2$ refers to the number of weeks between subculturing during the multiplication phase.

Table 8. Plant preservative mixture (PPM) vs. standard medium establishment rates.

\begin{tabular}{|c|c|c|c|c|c|c|c|}
\hline Genotype & Medium & Contam. rate ${ }^{y}$ & $\mathrm{n}$ & Avg. no. shoots & $95 \%$ conf. int. & Avg. shoot length $(\mathrm{mm})^{\mathrm{z}}$ & $95 \%$ conf. int. \\
\hline \multirow[t]{2}{*}{$05-830-50$} & PPM & $6 \%$ & 18 & 2.06 & $\pm(2.66,1.54)$ & 13.09 & $\pm(10.04,17.08)$ \\
\hline & Reg & $56 \%$ & 18 & 3.68 & $\pm(4.63,2.84)$ & 17.39 & $\pm(12.62,23.95)$ \\
\hline \multirow[t]{2}{*}{$06-1500-1$} & PPM & $39 \%$ & 18 & 2.48 & $\pm(3.27,1.80)$ & 10.09 & $\pm(7.32,13.90)$ \\
\hline & Reg & $50 \%$ & 18 & 2.87 & $\pm(3.82,2.07)$ & 8.41 & $\pm(5.90,11.98)$ \\
\hline \multirow[t]{2}{*}{$06-1500-6$} & PPM & $0 \%$ & 18 & 1.13 & $\pm(1.64,0.73)$ & 24.88 & $\pm(18.53,33.42)$ \\
\hline & Reg & $28 \%$ & 18 & 1.53 & $\pm(2.12,1.05)$ & 20.41 & $\pm(15.2,27.41)$ \\
\hline \multirow[t]{2}{*}{$06-1821-3$} & PPM & $11 \%$ & 18 & 1.22 & $\pm(1.96,0.66)$ & 13.60 & $\pm(9.10,20.32)$ \\
\hline & Reg & $44 \%$ & 18 & 1.87 & $\pm(2.94,1.04)$ & 10.91 & $\pm(6.79,17.55)$ \\
\hline \multirow[t]{3}{*}{$06-1819-1$} & PPM & $44 \%$ & 18 & 1.22 & $\pm(2.23,0.52)$ & 15.87 & $\pm(9.33,27.00)$ \\
\hline & Reg & $61 \%$ & 18 & 1.00 & $\pm(3.15,0.06)$ & 12.00 & $\pm(4.15,34.76)$ \\
\hline & & & & Prob $>F$ & & Prob $>F$ & \\
\hline Genotype (A) & & & & $<0.0001$ & & $<0.0001$ & \\
\hline Medium type (B) & & & & 0.10 & & 0.44 & \\
\hline $\mathrm{A} \times \mathrm{B}$ & & & & 0.44 & & 0.44 & \\
\hline
\end{tabular}

${ }^{\mathrm{y}}$ Percent of original starting buds that were contaminated.

${ }^{\mathrm{z}}$ Length measured in millimeters.

average shoot length were variable based on genotype (Table 3).

PPM reduced contamination rates during establishment for genotypes 05-830-50 and 06-1500-6 (Table 10). For all other individual genotypes, PPM had no significant effect on contamination rates (Table 10). No significant differences were detected for the number of shoots produced and shoot length between PPM and standard establishment mediums (Table 8).

\section{Multiplication}

Stabilization. After establishment, hybrid oak lines were transferred to the multiplica- tion phase. Stabilization occurred for an average of $153 \mathrm{~d}$ but varied significantly by genotype. The stabilization process identified lines that produced an increasing number of shoots during each successive multiplication cycle. Nineteen out of 39 genotypes stabilized in the multiplication phase are identified in Table 2 .

Zeatin PVP vs. standard medium. Modification of multiplication medium using PVP was trialed to determine its effects on preventing phenolic oxidation and subsequent damage to explants in vitro. Inclusion of zeatin and PVP in the establishment medium reduced the occurrence of phenolic oxidation after 2 weeks in multiplication medium for most of the genotypes, except 06-1819-1, compared with the control treatment (Table 11). Occurrence of phenolic oxidation was variable by genotype in the control medium. Genotype, medium type, and their combined interactions showed variable effects on the number of shoots produced and shoot length. For genotypes 06-1500-1 and 06-1821-2, the number of shoots produced was equal for the two medium types. Genotypes 05-830-50, 06-1500-6, and 06-1819-1 generated more shoots in the standard medium compared with the zeatin PVP medium. Most of the genotypes, aside from 06-1819-1, 
Table 9. Contamination rates during establishment by year and stock plant source location.

\begin{tabular}{|c|c|c|c|c|c|}
\hline $\mathrm{Yr}$ & $\mathrm{n}$ & Field & $\mathrm{n}$ & Growth chamber & Fisher's two-tailed \\
\hline 2016 & 545 & $19 \%$ & 605 & $5 \%$ & $<0.0001$ \\
\hline 2017 & 248 & $54 \%$ & 219 & $21 \%$ & $<0.0001$ \\
\hline 2018 & 162 & $49 \%$ & 187 & $7 \%$ & $<0.0001$ \\
\hline Total & 955 & & 1011 & & \\
\hline
\end{tabular}

Table 10. Plant preservative mixture (PPM) vs. standard establishment medium contamination rates.

\begin{tabular}{|c|c|c|c|c|c|}
\hline Genotype & PPM contaminated $(\%)$ & $\mathrm{n}$ & Standard contaminated $(\%)$ & $\mathrm{n}$ & Fisher's two-tailed \\
\hline $05-830-50$ & $6 \%$ & 18 & $56 \%$ & 18 & 0.0027 \\
\hline $06-1500-1$ & $39 \%$ & 18 & $50 \%$ & 18 & 0.7380 \\
\hline $06-1500-6$ & $0 \%$ & 18 & $28 \%$ & 18 & 0.0455 \\
\hline $06-1821-3$ & $11 \%$ & 18 & $44 \%$ & 18 & 0.2285 \\
\hline $06-1819-1$ & $44 \%$ & 18 & $61 \%$ & 18 & 0.5051 \\
\hline All & $20 \%$ & 90 & $46 \%$ & 90 & 0.0004 \\
\hline
\end{tabular}

Table 11. Presence of phenolic oxidation during establishment phase by genotype and medium type (control vs. zeatin PVP).

\begin{tabular}{lccccc}
\hline Genotype & Control (BAP) & $\mathrm{n}$ & Zeatin PVP & $\mathrm{n}$ & $P$ value \\
\hline $05-830-50$ & $90 \%$ & 20 & $0 \%$ & 20 & $<0.0001$ \\
$06-1500-1$ & $51 \%$ & 61 & $2 \%$ & 60 & $<0.0001$ \\
$06-1500-6$ & $10 \%$ & 58 & $0 \%$ & 58 & 0.0065 \\
$06-1821-3$ & $20 \%$ & 60 & $0 \%$ & 60 & 0.0003 \\
$06-1819-1$ & $20 \%$ & 20 & $0 \%$ & 20 & 0.106 \\
\hline
\end{tabular}

produced similar shoot lengths regardless of the medium treatment. For genotype 061819-1, the standard medium had longer average shoot lengths compared with the zeatin PVP medium (Table 6).

Subculture transfer time (1-5 vs. 2-2-2). For all genotypes observed, the subculturing frequency treatment had no effect on the number of shoots produced or the shoot length after a period of 6 weeks (Table 7). Differences were detected by genotype for the number of shoots and shoot length.

Shoots and tips. No differences were detected between the number of shoots produced or shoot length when multiplication cultures were started with either shoots or terminal tips. Differences were observed among genotypes (Table 4).

Rooting. The number of roots and root length were not statistically different between IBA and K-IBA auxin treatments (accessions 06-1500-6 and 06-1821-3). Differences were observed between genotypes, with 06-1500-6 producing significantly more roots compared with 06-1821-3, and no interactions were observed between genotype and medium. Root length between treatments and genotypes were not different (Table 12).

When a series of stabilized oak genotypes were trialed for rooting using only the auxin IBA, the percentage of shoots that produced roots varied by genotype from $60 \%$ to $100 \%$. The averages of the number of roots produced per shoot varied between one and three for almost all genotypes except 06-1500-1, which produced ten. Root length varied among genotypes, with 06-1500-6 and 061821-3 producing longer roots compared with all other genotypes. The number of roots produced and root length varied by genotype (Table 5).

\section{Discussion}

\section{Establishment}

Contamination rates varied between establishment year $(2016,2017,2018)$ and by source location where stock plants were harvested (field or growth chamber) (Table 9 ). Shoots harvested from the growth chamber had lower contamination rates compared with field-grown shoots. The variation in contamination rates by year could be attributed to differences in microbial phenology, depending on the progression of each growing season. Shoots used for force-flushing were collected during winter dormancy. In early spring, cold temperatures and limited availability of substrates suitable for microbial development may explain the limited microbial activity and contamination rates from dormant shoots harvested at this time of year (Nedwell, 1999). The same disinfecting protocol was used for each growing season, leading to the conclusion that differences in microbial activity or abundance could explain differences in contamination rates. The observation in this study of higher contamination rates occurring in stock plants grown in field conditions compared with protected settings, such as a greenhouse, agrees with the findings of Niedz and Bausher (2002).

Establishment rates were highly variable and dependent on individual genotypes (Table 3). Some genotypes exhibited as much as $100 \%$ responsiveness in establishment, while others were as low as $0 \%$. Likewise, average shoot length and number of shoots produced from single starting nodes were also genotype specific. The genotypespecific response with some individuals tolerating and performing better than others in a tissue culture environment has been found in other oak tissue culture studies during the establishment, multiplication, and rooting phases (Herrmann and Buscot, 2008; San-José et al., 1988; Vengadesan and Pijut, 2009; Vieitez et al., 1993, 1994, 2009) and in oak somatic embryogenesis (Corredoira et al., 2019; Vieitez et al., 2012).

Responsiveness to the establishment phase was unaffected by the individual year that establishment was trialed. Genotypes that had previously been established in culture and moved to the multiplication phase had the capacity to re-establish and stabilize in subsequent years (Table 2). This response was like the findings of Martinez, who in 2008 established oak somatic embryogenesis lines from the same genotypes of trees used for tissue culture by Vidal et al. in 2003 (Martínez et al., 2012; Vidal et al., 2003). This finding suggests that genotype is a significant factor leading to successful establishment and multiplication of oaks in tissue culture. While genotype specificity remains a significant factor in successfully growing oaks in a tissue culture system, other dynamics such as phenological development throughout the year (Romano and Loução, 1992), topophysical position (Evers et al., 1993), and age of the stock plant also affect success rates (Evers et al., 1993; Romano and Loução, 1992; Vieitez et al., 1993, 1994). The oak tissue culture process used in this study proved to be time-consuming, with establishment periods limited to the spring of each year and with low success rates depending on genotype. The screening process of trialing many different hybrid oaks in the establishment phase was labor intensive and limited by both the capacity of technicians (required staff hours) and logistical challenges. Logistics include the management of harvesting, disinfection, and establishment of germplasm from many stock plants developing at different rates during the start of the growing season.

One of the most important findings from this study is the identification of specific genotypes that have the capacity for establishment, multiplication, shoot growth, elongation, rooting, and repeat establishment (Tables 2 and 3). While a relatively large number of hybrid oaks show at least some capacity to produce elongated shoots during the establishment phase (Table 3), this fact 
Table 12. Effect of auxin type (IBA vs. K-IBA) on rooting of two genotypes of hybrid oaks.

\begin{tabular}{|c|c|c|c|c|c|c|c|}
\hline Genotype & Auxin & $\mathrm{n}$ & Contam. rate ${ }^{z}$ & Avg. no. roots & $95 \%$ conf. int. & Root length $^{\mathrm{y}}$ & $95 \%$ conf. int. \\
\hline $06-1500-6$ & IBA & 15 & $20 \%$ & $9.32 \mathrm{a}$ & $\pm(13.00,6.25)$ & $11.81 \mathrm{a}$ & $\pm(15.55,8.58)$ \\
\hline $06-1500-6$ & K-IBA & 15 & $0 \%$ & $8.14 \mathrm{a}$ & $\pm(11.21,5.57)$ & $13.83 \mathrm{a}$ & $\pm(17.4,10.66)$ \\
\hline $06-1821-3$ & IBA & 15 & $20 \%$ & $1.83 \mathrm{a}$ & $\pm(3.63,0.64)$ & $10.62 \mathrm{a}$ & $\pm(15.05,6.96)$ \\
\hline \multirow[t]{2}{*}{$06-1821-3$} & K-IBA & 15 & $0 \%$ & $1.11 \mathrm{a}$ & $\pm(2.40,0.56)$ & $11.30 \mathrm{a}$ & $\pm(15.58,7.71)$ \\
\hline & & & & Prob $>F$ & & Prob $>F$ & \\
\hline \multicolumn{4}{|c|}{ Genotype (A) } & $<0.0001$ & & 0.329 & \\
\hline \multicolumn{4}{|c|}{ Rooting medium type (B) } & 0.346 & & 0.480 & \\
\hline \multicolumn{2}{|l|}{$\mathrm{A} \times \mathrm{B}$} & & & 0.851 & & 0.741 & \\
\hline
\end{tabular}

${ }^{\mathrm{z}}$ Percent of original starting buds that were contaminated.

${ }^{\mathrm{y}}$ Root length measured in millimeters.

did not guarantee that these same genotypes were able to stabilize in the multiplication phase. Identification of genotypes that have the capacity to tolerate the tissue culture environment represents a major step toward developing a clonal oak propagation system and releasing oak cultivars.

\section{Plant preservative mixture}

Plant Preservative Mixture (PPM) is a fungicidal/biocidal tissue culture additive that was trialed in 2018 to determine its effect on reducing contamination rates during the establishment phase. Contamination rates during establishment were shown to vary significantly by year (Table 9) and location where stock plants were sourced (field vs. growth chamber). Field-grown shoots had significantly higher contamination rates compared with shoots force-flushed in a growth chamber. To reduce contamination rates, PPM was trialed. All cultures that had PPM additions showed lower contaminant rates, but the reductions were only statistically significant for two genotypes (05-830-50 and 06-1500-6) (Table 10). Significant differences were detected between PPM and the standard medium, for the number of shoots produced or shoot length (Table 8). As with other establishment studies, significant differences for the number of shoots and shoot length varied by genotype. This study did not continue the examination of PPM use into the multiplication phase, so what the long-term effects of PPM are on oak shoot development and growth remains unclear.

\section{Multiplication}

Stabilization. As with the establishment phase, not all oak genotypes were amenable to the multiplication phase of tissue culture. In multiplication, some hybrid lines perished over successive multiplication cycles while others stabilized. The number of shoots, shoot length, and the number of leaves produced varied in the multiplication phase, based on specific genotypes (Tables 6, 7, and 4). Once hybrid lines reached a stabilization threshold, they appeared to have the capacity to grow in multiplication for an indefinite amount of time. For example, hybrid lines established in 2014 were still actively maintained in multiplication through 2018. In other oak tissue culture studies, the stabilization process took 4 to 12 months (Herrmann and Buscot, 2008; Vieitez et al., 2009). For most of the hybrid oak lines under assessment, stabilization was detected in as little as 3 months and took $153 \mathrm{~d}$ on average.

After identifying genotypes that could stabilize (Table 2), we used these lines for experimentation and modification of multiplication phase protocols. Other researchers who have undertaken oak tissue culture work have followed a similar path of identifying highly productive lines and then using them for experimentation (Vieitez et al., 2009). The capacity to re-establish and stabilize the same genotypes over multiple years into the multiplication cycle was a significant finding. Genotypes 06-1819-1, 06-1500-1, and 061500-6 are examples of hybrid lines that could be re-established and stabilized (Table 2). The re-establishment of these genotypes allowed this research to be replicable and confirmed that genotype is a significant factor when attempting to grow oaks in tissue culture. This finding suggests that specific genotypes have the capacity to re-stabilize in multiple years. The result advocates that the genotype effect may have more importance than other factors (such as the physiological or phenological stage of the stock plants at the time of establishment).

Zeatin PVP vs. standard medium. Polyvinylpyrrolidone (PVP) is a water-soluble polymer that can form complexes with polyphenols through hydrogen bonding (Porebski et al., 1997). Oaks are known to contain high quantities of polyphenols such as ellagitannins (hexahydroxydiphenoylesters) and condensed tannins (proanthocyanidins) (Scalbert et al., 1988). These are released as lysate when mechanical damage occurs to cells when cutting stems during the tissue culture process. When these polyphenols are released into a tissue culture medium, they oxidize, turning the medium dark brown, and they can be damaging to explants. In oak tissue culture, PVP has been added to the culture medium to eliminate or reduce occurrence of oxidation caused by phenolic release. A 1992 oak tissue culture study by Romano and Loução noted that a decline in explant survivability in the establishment phase was due to phenolic exudation in $Q$. robur. In this 1992 study, a series of treatments included the use of PVP and a combination of ascorbic and citric acid to reduce oxidation damage. Treatments, including PVP, proved ineffective at reducing browning and oxidation of the medium. The investigators resorted to transferring cultures with large amounts of phenolic oxidation within $48 \mathrm{~h}$ after establishment into a fresh medium (Romano and Loução, 1992) to avoid contact with tannins in the culture. A 1994 study examined the effects of pretreating $Q$. suber and $Q$. petrea cultures with phenolic-inhibiting compounds and observed that PVP prevented browning from oxidation but caused poor shoot growth (Toth et al., 1994).

PVP has been used in column chromatography as a solid phase with a phosphate buffer as an eluant to extract cytokinins from plant tissue (celery seed) (Biddington and Thomas, 1976). This study observed that $\mathrm{pH}$ played a significant factor in the binding affinity of cytokinins to PVP. It was observed that as $\mathrm{pH}$ lowered, cytokinins were released with the use of less elution buffer. This finding suggests that $\mathrm{pH}$ plays a critical role in the capacity for PVP to bind or release cytokinins into a buffer solution. It was also observed that different cytokinins were extracted as elution volumes increased. Zeatin released at the lowest elution volumes, followed by kinetin and then BAP. This result suggests that binding capacity of these plant hormones to PVP is dependent on their chemical structure, $\mathrm{pH}$, and quantities of elution buffer in a solution (Biddington and Thomas, 1976). As zeatin requires some of the lowest amounts of elution buffer needed to be extracted from a PVP column, an experiment was designed to determine if its low binding strength would make this cytokinin more plant-available in tissue culture medium. Browning of the medium due to phenolic oxidation is most observable directly after mechanical damage to shoots when cutting nodes during the establishment phase, or shoots during the multiplication phase.

This experiment measured whether PVP could be used to reduce damage and explant attrition during the multiplication phase by reducing phenolic oxidation compared with the standard BAP medium. The zeatin PVP medium effectively controlled phenolic oxidation in $98 \%$ to $100 \%$ of the cultures in this treatment. Comparatively, the standard BAP medium showed variable results, with phenolic exudation affecting between $10 \%$ and $90 \%$ of the cultures based on genotype (Table 11). The variable results for the BAP treatment have suggested that individual genotypes may produce varying quantities of phenolics. These findings offer that oxidation may only negatively affect individual lines. 
The number of shoots and average shoot length differed by genotype, medium treatment, and their interaction (Table 6). For genotypes 05-830-50, 06-1500-6, and 061819-1, the zeatin PVP treatment produced significantly fewer shoots compared with BAP alone. Within individual genotypes, both treatments produced equal shoot lengths for all cultures (aside from 06-1819-1, which had shorter shoots in the zeatin PVP medium). These results show that the effectiveness of PVP was variable by genotype (Table 6). Qualitatively, leaves grown in the zeatin PVP medium were a lighter green color, potentially indicating a nutrient deficiency, compared with the BAP control medium. This finding suggests that the first 2 weeks of the multiplication cycle are a critical period in the development and growth of oaks in vitro.

While PVP was an effective treatment for reducing phenolic oxidation, the negative effects on shoot growth limited its usefulness. We observed that phenolic oxidation in the multiplication phase was significantly less damaging than in the establishment phase. In the establishment phase, single nodes were placed in the medium. and phenolic browning could potentially fully surround the explants. However, during multiplication, the shoots were longer, and the primary source of phenolics was from the cut end of the shoot. For longer explants, the total overall surface area exposed to phenolic oxidation was less compared with the short nodes used in establishment. During the multiplication phase it was observed that shoots could generally multiply in the presence of small amounts of oxidized phenolics. Browning and damage caused by phenolic exudation was not a major cause of mortality during the multiplication phase.

San-José et al. (1988) used zeatin for multiplication and shoot elongation of $Q$. robur cultures. In this study, the researchers moved shoots growing in a BAP medium after 4 weeks into a medium with various concentrations of zeatin. They noted that for a single clone, shoot length increased in the medium containing zeatin, ranging from 0.1 to $1.0 \mathrm{mg} / \mathrm{L}$, compared with a BAP medium. In the same study, another $Q$. robur clone showed no significant differences between the zeatin or BAP treatments (San-José et al., 1988). This finding was like the results of our study, which showed varying results based on genotype.

In a different study, various concentrations of BAP and zeatin in the multiplication phase were compared in $Q$. suber cultures. That study showed that explants in a BAP medium produced more shoots that were longer, compared with those grown in the zeatin medium (Romano and Loução, 1992). These results agreed with the findings of our study, in which the hybrid oaks generally showed a larger number of shoots produced in BAP medium. While not significantly different in all cases, average shoot length was lower in most oaks cultured in the zeatin medium (Table 11).
Subculture transfer time (1-5 vs. 2-2-2). An experiment was conducted to determine if changing the transfer frequency of subculturing affected the capacity of hybrid oaks to multiply. If frequency had no effect, then it would be possible to reduce the labor associated with making a medium and the time for a technician to carry out subculturing. Two transfer frequencies were trialed using four genotypes. For four genotypes and after forty replications, it was observed that the number of shoots and shoot length were statistically equal between treatments (Table 7). The major differences detected in shoot growth were among individual genotypes, and these differences were not attributed to transferring frequency. No interactions were observed between treatment or treatment by genotype. These experiments demonstrated that it is possible to reduce labor during the multiplication process by using the 1- to 5week transfer frequency.

Shoots and tips. Current oak tissue culture methods do not have the capacity to grow shoots indeterminately. Shoots display an episodic growth cycle (Herrmann and Buscot, 2008); after setting a terminal bud, the explants tend to decline due to shoot tip necrosis (Schwarz and Schlarbaum, 1993). Previous research determined that placing shoots horizontally in tissue culture medium during multiplication promoted the development of lateral nodes that develop new shoots (San-José et al., 1988). Improved efficiency (production of a larger number of shoots) was achieved by removing the terminal bud when initiating a new multiplication phase (Vieitez et al., 1993, 2009). Our results using hybrid oaks suggest that the terminal buds can successfully be used in the multiplication phase. Both shoots and tip cultures produced an equal number of new shoots during the multiplication phase. For both treatments (shoot vs. tip), the newly flushed shoots were equal in length (Table 4). Oaks in vitro and under field conditions generated a telescoping growth pattern, where internodal length decreased for nodes closer to the terminal bud. As a result, when apical buds and the associated 3-mm shoot tissues were harvested, a series of lateral buds were collected. In tip cultures, some of the terminal and lateral buds would develop into multiple new shoots by the end of the multiplication phase. This occurrence suggests that terminal buds can be used in the multiplication phase of oak tissue culture and provide more explant material, increasing overall multiplication efficiency.

Rooting. Significant differences were observed among genotypes, with 06-1500-6 producing on average between eight and nine roots per shoot, compared with one root per shoot for 06-1821-3 (Table 12). While differences were observed between genotypes, the two forms of IBA showed no difference in their capacity to induce rooting. As a result, IBA was selected for further experimentation on rooting hybrid oaks.

A second rooting study was conducted to determine the capacity of various hybrid oak genotypes to produce roots. Six genotypes were selected and trialed using the standard rooting protocol. Results showed that all genotypes produced roots with an IBA treatment, but the number roots produced varied by genotypes, between $67 \%$ and $100 \%$. Differences between genotypes were observed, with $06-1500-6$ producing significantly more roots compared with other genotypes. Mean root length was greatest for 06-1500-6 and 06-1821-3, both of which produced significantly longer roots compared with other genotypes (Table 5). Callus development was ubiquitous on all shoots after the IBA treatment and when growing in the PGR-free medium. In short shoots, calli were at times as large as the exposed shoot tissue. Calli appeared to be required for inducing roots because no roots were observed in shoots that did not produce calli. Roots arising from callus tissue could potentially lack connective xylem to the main shoot. If this connection did not form, there could be an issue for continued growth during acclimatization. No anatomical studies were undertaken to determine if xylem connectivity was present. Although differences were observed in both number of roots and root length, the fact that all shoots produced roots demonstrated that the rooting phase of tissue culture is unlikely the limiting factor for the development of clonally propagated oaks.

One limiting factor affecting cultures during rooting was the occurrence of shoot tip necrosis. Shoot tip necrosis has been commonly reported during oak micropropagation, with the terminal bud of a newly developed shoot dying in culture (Schwarz and Schlarbaum, 1993; Vieitez et al., 1994, 2009). While the 6-week multiplication cycle is a standard time scale for oak multiplication, this period may be too long for certain genotypes and result in shoot tip necrosis. For genotypes that grow quickly in the tissue culture environment, evaluation and subculturing - before the standard 6-week period - could be conducted when individual shoots reach their maximum growth point. Modification of harvesting shoots for rooting or continuous multiplication cycles could reduce occurrence of shoot tip necrosis. In our study, shoot tip necrosis occurred in the establishment, multiplication, and rooting phases of tissue culture. Initial pilots of the rooting method placed shoots in IBA medium for 1 week, followed by 4 weeks in a PGRfree medium with charcoal. Four weeks in a PGR-free medium tended to result in shoot tip necrosis occurring in a large number of shoots, and therefore the method was modified to reduce this time period to 2 weeks (1 week IBA, 2 weeks PGR-free).

\section{Conclusion}

The development of clonally propagated oaks has concurrently been a long-term goal and challenge for the selection of superior oak genotypes. This study demonstrates the viability of clonally propagated oaks using tissue culture. Genotype specificity remains the 
single largest factor that affects the successful establishment, multiplication, and rooting of oaks in tissue culture. As a result, the screening of many UHI hybrid white oak genotypes for their capacity to establish, multiply, and root in tissue culture is a crucial step toward development of oak cultivars. These results lay the foundation for large-scale production of stress tolerant oaks for the urban environment and provide a path for introduction of cultivars from the UHI breeding program.

\section{Literature Cited}

Abrams, M.D. 1990. Adaptations and responses to drought in Quercus species of North America. Tree Physiol. 7(1-4):227-238.

Amissah, J.N. and N. Bassuk. 2009. Cutting back stock plants promotes adventitious rooting of stems of Quercus bicolor and Quercus macrocarpa. J. Environ. Hort. 27(3):159-165.

Biddington, N.L. and T.H. Thomas. 1976. Effect of $\mathrm{pH}$ on the elution of cytokinins from polyvinylpyrrolidone columns. J. Chromatography 121(1):107-109.

Brennan, A.N., V.C. Pence, M.D. Taylor, B.W Trader, and M. Westwood. 2017. Tissue culture using mature material for the conservation of oaks. HortTechnology 27:644-649.

Cavender-Bares, J. 2019. Diversification, adaptation, and community assembly of the American oaks (Quercus), a model clade for integrating ecology and evolution. New Phytol. 221(2):669692.

Coggeshall, M.V. 1996. Oak grafting techniques. Proc. Intl. Plant Prop. Soc. 46:481-486.

Corredoira, E., S.A. Merkle, M.T. Martínez, M. Toribio, J.M. Canhoto, S.I. Correia, A. Ballester, and A.M. Vieitez. 2019. Non-zygotic embryogenesis in hardwood species. Crit. Rev. Plant Sci. 38(1):29-97.

Denig, B.R., P.F. Macrae, Jr., X. Gao, and N.L. Bassuk. 2013. Clonal propagation of oak hybrids using a modified layering technique. Proc. Intl. Plant Prop. Soc. 1055:253-262.

Denig, B.R., P.F. Macrae, Jr., X. Gao, and N.L. Bassuk. 2014. Screening oak hybrids for tolerance to alkaline soils. J. Environ. Hort. 32(2):71-76.

Dirr, M.A. 1987. The reference manual of woody plant propagation: From seed to tissue culture; A practical working guide to the propagation of over 1100 species, varieties and cultivars. 2nd ed. Stipes Publishing, Champaign, IL.

Evers, P., E. Vermeer, and S. Van Eeden. 1993. Rejuvenation of Quercus robur. Ann. Sci. For. $50: 330 \mathrm{~s}-335 \mathrm{~s}$
Griffin, J. and N. Bassuk. 1996. Preliminary progress on the asexual propagation of oaks. Proc. Intl. Plant Prop. Soc. 46:487-494.

Herrmann, S. and F. Buscot. 2008. Why and how using micropropagated trees rather than germinations for controlled synthesis of ectomycorrhizal associations, p. 439-465. In: A. Varma (ed.). Mycorrhiza. Springer, Berlin.

International Oak Society. 2018. Oak names database. 7 May 2018. <http://www.oaknames.org/ search/index.asp $>$.

Kramer, A.T. and V. Pence. 2012. The challenges of ex situ conservation for threatened oaks. Intl. Oaks. 23:91-108.

Martínez, T., N. Vidal, A. Ballester, and A.M Vieitez. 2012. Improved organogenic capacity of shoot cultures from mature pedunculate oak trees through somatic embryogenesis as rejuvenation technique. Trees (Berl.) 26(2):321-330.

Nedwell, D.B. 1999. Effect of low temperature on microbial growth: Lowered affinity for substrates limits growth at low temperature. FEMS Microbiol. Ecol. 30(2):101-111.

Niedz, R.P. 1998. Using isothiazolone biocides to control microbial and fungal contaminants in plant tissue cultures. HortTechnology 8:598-601.

Niedz, R.P. and M.G. Bausher. 2002. Control of in vitro contamination of explants from greenhouseand field-grown trees. In Vitro Cell. Dev. Biol. Plant 38(5):468-471.

Nixon, K. 1997. Quercus, p. 445-506. In: Flora of North America, North Mexico Editorial Committee (eds.). 1993+. Flora of North America North of Mexico. Vol. 3. Oxford Univ. Press, New York.

Osuna, L.J., D.D. Baldocchi, H. Kobayashi, and T.E. Dawson. 2015. Seasonal trends in photosynthesis and electron transport during the Mediterranean summer drought in leaves of deciduous oaks. Tree Physiol. 35(5):485-500.

Porebski, S., L.G. Bailey, and B.R. Baum. 1997. Modification of a CTAB DNA extraction protocol for plants containing high polysaccharide and polyphenol components. Plant Mol. Biol. Rpt. 15(1):8-15.

Raupp, M.J., A.B. Cumming, and E.C. Raupp. 2006. Street tree diversity in eastern North America and its potential for tree loss to exotic borers. Arboric. Urban For. 32(6):297-304.

Romano, A. and M.M. Loução. 1992. Micropropagation of mature cork-oak (Quercus suber L.): Establishment problems. Scientia Gerundensis. 18:17-27.

San-José, M.C., A. Ballester, and A.M. Vieitez. 1988. Factors affecting in vitro propagation of Quercus robur L. Tree Physiol. 4(3):281-290.
Santamour, F.S. and M.V. Coggeshall. 1996. Graft incompatibility in red oak: Theory and practice. Proc. Int. Plant Propagators Soc. 46:476-480.

Scalbert, A., B. Monties, and J.M. Favre. 1988. Polyphenols of Quercus robur: Adult tree and in vitro grown calli and shoots. Phytochemistry 27(11):3483-3488.

Schwartz Sax, M. 2019. Queries in Quercus: From the development of a tissue culture clonal propagation system to the evaluation of stress tolerant hybrid white oaks for the urban environment. Cornell Univ., Ithaca, PhD Diss. Abstr. 13861794.

Schwarz, O.J. and S.E. Schlarbaum. 1993. Axillary bud proliferation of 2 North American oak species: Quercus alba and Quercus rubra. Annales des sciences forestières 50:340s-343s.

Sjöman, H., A.D. Hirons, and N.L. Bassuk. 2018. Improving confidence in tree species selection for challenging urban sites: A role for leaf turgor loss. Urban Ecosyst. 21(6):1171-1188.

Toth, K., T. Haapala, and A. Hohtola. 1994. Alleviation of browning in oak explants by chemical pretreatments. Biol. Plant. 36(4):511-517.

Vengadesan, G. and P.M. Pijut. 2009. In vitro propagation of northern red oak (Quercus rubra L.). In Vitro Cell. Dev. Biol. Plant 45(4):474-482.

Vidal, N., G. Arellano, M.C. San-José, A.M. Vieitez, and A. Ballester. 2003. Developmental stages during the rooting of in-vitro-cultured Quercus robur shoots from material of juvenile and mature origin. Tree Physiol. 23(18):1247-1254.

Vieitez, A.M., M. C. San-José, and E. Vieitez. 1985. In vitro plantlet regeneration from juvenile and mature Quercus robur. L. J. of Hort. Sci. 60(1):99-106.

Vieitez, A.M., F. Pintos, M.C. San-José, and A. Ballester. 1993. In vitro shoot proliferation determined by explant orientation of juvenile and mature Quercus rubra L. Tree Physiol. 12(2):107-117.

Vieitez, A.M., M.C. Sánchez, J.B. Amo-Marco, and A. Ballester. 1994. Forced flushing of branch segments as a method for obtaining reactive explants of mature Quercus robur trees for micropropagation. Plant Cell Tissue Organ Cult. 37(3):287-295.

Vieitez, A.M., E. Corredoira, A. Ballester, F. Muñoz, J. Durán, and M. Ibarra. 2009. In vitro regeneration of the important North American oak species Quercus alba, Quercus bicolor and Quercus rubra. Plant Cell Tissue Organ Cult 98(2):135-145.

Vieitez, A.M., E. Corredoira, M.T. Martínez, M.C. San-José, C. Sánchez, S. Valladares, N. Vidal, and A. Ballester. 2012. Application of biotechnological tools to Quercus improvement. Eur. J. For. Res. 131(3):519-539. 